\title{
The Effectiveness of Retraining Attribution Styles (Cognitive Therapy) on Dimensions of Family Functioning in Divorce Applicant Couples
}

\author{
Hassan Zareei Mahmoodabadi ${ }^{1}$, Fatemeh Bahrami ${ }^{1}$, Ahmad Ahmadi ${ }^{1}$, \\ Ozra Etemadi ${ }^{1} \&$ Maryam Sadat Fatehi Zadeh ${ }^{1}$ \\ ${ }^{1}$ Faculty of Educational and Psychology, Department of Counseling, University of Isfahan, Isfahan, Iran \\ Correspondence: Hassan Zareei Mahmoodabadi, Faculty of Educational and Psychology, Department of \\ Counseling, University of Isfahan, Isfahan, Iran. Tel: 98-913-257-1279. E-mail: zareei_h@yahoo.com
}

Received: January 4, 2012

Accepted: February 20, 2012 Published: June 1, 2012

doi:10.5539/ijps.v4n2p257

URL: http://dx.doi.org/10.5539/ijps.v4n2p257

\begin{abstract}
The aim of this study was to determine the effectiveness of retraining attribution styles (cognitive therapy) on dimensions of family functioning in divorce applicant couples. The research design was pre-test and post- test with control group. 20 couples (40 people) were selected by the purposeful sampling method. They were randomly assigned into experimental and control groups. The experimental group was exposed to training over 8 weekly 1.5 -hr sessions and the control group was in the waiting list. The instrument of this study was Family Assessment Device (FAD). The collected data was analyzed by a MANOVA, an ANOVA and an Independent-samples $t$ test. Results showed that training can improve family functioning in couples. The study suggests that this research can also be applied to clinical and counseling environments to help problematic couples.
\end{abstract}

Keywords: ANOVA, attribution styles, cognitive therapy, divorce, family function, MANOVA

\section{Introduction}

Marital interactions have multiple functions which can be examined from different aspects, whether the couple has offspring or not (Epstein \& Baucom, 2002). A family plays a decisive role in the maintenance of individuals' physical and mental health; in addition, it has a significant effect on the society's health as well as on the prevention of different types of social problems (Gottman, 1996). Unfortunately, the divorce rate and marital difficulties are on the rise. These problems deal a serious blow to family members. Davoodi (2009) estimated the number of divorces and marriages registered in Iran in 2009 to be 94,040 and 778,022 respectively, with the divorce rate standing at $19.3 \%$. Divorce is a lengthy process, beginning with a state of turbulence or dissatisfaction and ending in reconciliation or breakdown (Finzi, Kohan \& Ram, 2000). Its rate has been following an upward trend worldwide over the last decade (Young \& Long, 1998). Out of every one-thousand marriages registered in Iran roughly 200 end up in divorce (Zarei \& Younesi, 2009). Divorce separates the marital subsystems, leaves a scarf on all the members of family sbsystems, and affects their relationships with other sub-systems (Avidan, Yahia, \& Greenbaum, 2009). Nowadays, many marriages break down well before the wedding ceremony or just a short time after the wedding ceremony. (Kalmjin \& Unk, 2007). If we develop an understanding of the causes of marital breakdowns, we can work out a solution to offer assistance to couples on the verge of divorce. Divorce applicant couples have serious problems in the dimensions of family function (Zarei \& Younesi, 2009).

Family functioning or efficiency is a joint effort to establish and maintain equilibrium in the family (Holley, 2006). A desirably functioning family constitutes an open system in which the members are emotionally connected to one another. At the same time, they are encouraged to extend their personal identity (Sutton, 1998). The atmosphere of such a family is full of platonic love to, and acceptance of, every member. As a result of this love and acceptance, the family can tolerate conflicts and respond to the members' appeal for help with alacrity (Leonard \& Roberts, 1998). Family function, sometimes referred to as family efficiency, has two major components, namely, inter-familial and intra-familial. Therefore, it is both a function of social, cultural and economic conditions of a society and a function of the members' configuration and the family's structure (Zarei \& Younesi, 2009). The criterion for the family functioning is not the nonexistence of mental tension, conflicts and problems; rather, it is the extent to which a family is capable of performing its tasks and functions, which in turn depends upon 
coexistence and the couples' adjustment capability (Epstein \& Baucom, 1983).

Nowadays, cognitive factors are the most important ones in achieving an understanding of the dynamism of marital life and changes in marital relationships (Baucom \& Epstein, 1990). The wish to have a wholesome life and a peaceful family is the presupposition of youngsters before they come of age despite all the marital failures and breakdowns occurring in the society. This presupposition is a process in which the youngsters seek a serene future (Datilo \& Epstein, 2005).

In cognitive therapy, the fundamental assumption is that an individual's interpretation of an event determines his type of behavior and typically his feeling (Layhi, 2008). The fact is that many couples are taken by surprise when they come to the conclusion that their feeling is a function of the way they contemplate the events and they can transform their feeling by changing their interpretation of reality to a large extent. Beck's cognitive therapy model puts emphasis on the pivotal role of thinking in anxiety, rage and depression aspects (Layhi, 2008). Cognitive technique is a set of methods in which the counselor urges the clients to change their deviated, inefficient patterns to experience a shift in their thoughts and behavior.

Among cognitive theories used to define marital conflicts, attribution styles have a special position (Kelly, 1973). According to this pattern, the individuals causal inference made through an observation of the spouse's behavior highly influences the level of their satisfaction derived from the relationship (Finchaum \& Bech, 1999). Baucom and Hosiers (1989) found that helpless couples attribute their spouses' negative behavior associated with the lack of cooperation to internal factors, through which they convey their maximum miss-behave; On the contrary, they further attribute their spouses' positive and awarding behavior to external factors. Also, helpless couples put stress on the negative behavior of their spouses and fail to take their positive behavior into account. While successful couples emphasize the positive behavior of their spouses, that is, they do not pay attention to their likely negative behavior (Goldenberg \& Goldenberg, 2008).

The main assumption of the application of attributional retraining for resolving marital problems is that couples have a specific perception of events which may or may not be in accordance with reality. The way these perceptions are formed should be examined to determine whether all the infrastructural information of these perceptions is available, valid and complete. If one of the couples interprets the criticism of his/her spouse as an attempt at rejection, it should be examined whether the other party has really intended to convey the rejection message to the spouse through the criticism, or it has been simply a misconstruction. Most couples act selectively in their perceptions and tend to pay no attention to the evidence and factors in conflict with their assumption of the perceptible events (Weary \& Harvey, 2001).

The dominant part of the concept and definition to which couples refer to explain one another's behavior is the attribution or explanation they have provided for behavior. According to Fosterling (2001), people dependent upon one another are interested in explaining the behavior of each other. Each wants to know: what the other party really likes, how he/she can live up to the other party's expectations in the future, and under what circumstances they should change their behavior. In addition, the motivation for explanation, prediction and interpretation of interpersonal events grows when they are negative, important and self attributed (Gottman, 1983).

Holtzwrth, Munero and Jacobson (1985) have reported that most married people analyze their spouses' behavior, particularly the negative ones. For instance, they interpret the aggressive and lukewarm behavior of their spouse as ill humor. When they are asked about the reason of such behavior, here is what they say: "I have had an exhausting, bad day."

In addition, our conclusions as to what other individuals undertake are of importance. They determine our reactions to others and affect our decisions (Walsh, 1988). In a study on the effectiveness of group behavioral-cognitive therapy in women's marital satisfaction, Amani (2003) found that such a therapy results in a rise in women's marital satisfaction and family function, a drop in depression, development of realistic attitude towards marital relationships, and an increase in the quality of sexual and affective relationships in women's marital lives. Also, Baucom and Epstein (1990) yielded similar findings on the effect of offering cognitive therapy to conflicting couples through the single case method. Hosseini (2000) argued that the combination of a problem-solving program with relationship training could be effective in reducing marital helplessness.

Rezakhoo and Younesi (2003) conducted a study on the role of retraining attribution styles and increase in the marital satisfaction of maladjusted couples and found attribution training and cognitive therapy effective. Zarei and Younesi (2009) conducted a research on the effect of cognitive technique training on the improvement of family function among maladjusted couples, and found this technique and its role in the promotion of family function effective. 
Baucom and Epstein (1990) have devised a special therapy program through combining a part of works performed in the field of unrealistic expectations and marital attribution, which relates to changes in the ineffectual and deviated marital cognition. In this method, we first focus on the couples' attribution styles and then emphasize internal versus external, specific versus global, and stable versus instable attribution dimensions.

Couples' attribution stems from a series of experiences gained in the marital interactions. When in a situation, a type of behavior or problem occurs, similar situations with similar attributions are interpreted and perceived; in such situations, the behavior of the couples depends upon the attributions they have formed (Dattilo \& Epstein, 2005). Generally, neutral and compatible attributions lead to the kinds of behavior that enhance problem-solving, while undesirable attributions result in the kinds of behavior that prolongs the problems (Boss, 1993).

The relationship between attributions and marital satisfaction has been mainly examined through longitudinal studies. In early research, attributions would be considered predictors of marital quality. Recent findings also confirm the results of early research which characterized attributions as predictors of the ongoing marital satisfaction (Bradbury \& Fincham, 1990).

Many studies have examined the application of attributional retraining to raise resistance and function following failure (Teasdale, 1993). Fostering (2001) concluded that the trainings had changed cognition and behavior in keeping with expectations following a review of 15 studies on the effectiveness of attribution retraining. Epstein and Baucom (1993) also succeeded in dispelling the belief that misbehavior on the part of others is deliberate by attribution retraining methods with the help of which the aggressive behavior of subjects was reduced. As for resolving marital problems, Carlyon (1997) applied a special therapy program with an emphasis on marital attributions, which ended in a change in ineffectual and deviated marital cognition.

Regarding the increasing rate of divorce in the Iranian society and the harms resulting from that and the concern of couples in the marital life for increasing marital satisfaction and promoting family function, the current research was conducted to improve family function dimensions of divorce applicant couples. Therefore, the research intends to answer the question of whether cognitive techniques or attribution retraining can promote family functioning of the divorce applicant couples. Then, the hypothesis of this research was:

1) Retraining attribution styles leads to the improvement of "roles" in divorce applicant couples.

2) Retraining attribution styles leads to the improvement of "communication" in divorce applicant couples.

3) Retraining attribution styles leads to the improvement of "problem solving" in divorce applicant couples.

4) Retraining attribution styles leads to the improvement of "affective responsiveness" in divorce applicant couples.

5) Retraining attribution styles leads to the improvement of "affective involvement" in divorce applicant couples.

6) Retraining attribution styles leads to the improvement of "behavior control" in divorce applicant couples.

\section{Method}

\subsection{Participants}

This research was quasi-experimental and was based on a pre test- post test design with a control group. The sample of the research was from among the divorce applicant couples who referred to the Yazd Family Court, from September 2010 to March 2011. The researcher conducted a primary interview with them through a semi-structure interview based on the Mac Master pattern. Finally, 40 people (twenty couples) were selected by purposeful sampling method and randomly classified into two groups including an experiment and a control group. The average age of the divorce applicant women and men in the experiment group was 23 and 27 respectively and 22 and 28 in the control group.

The criteria to be qualified for the research were as follows: assurance was obtained that the couples had taken at least their high school diploma, that they had attended the sessions of their own volition (i.e., both should have signed the counseling contract), that they had not got married before, and that they did not have backgrounds of any personality disorders.

\subsection{Procedure}

First of all, divorce applicant couples were categorized into experiment and control groups. Then, the experiment group received trainings for 8 weeks ( 1.5 hours session each week). The trainings were offered by a counselor trained under the supervision of a cognitive therapy expert. All combinational training programs had been confirmed by five counseling and psychology experts. The reason why this program had been selected was due to the frequency of attributions in relationships. No training was offered to the control group; however, when the 
trainings of the experiment group were completed, the control group was invited to take part in the training sessions regarding the moral considerations. (It should be mentioned that both groups underwent FAD pre-test first, and then counseling sessions were arranged just for the test group. Finally, the post-test was administered for both groups after eight sessions.)

\subsection{Measurement}

Family Assessment Device (FAD) is a 60 - item scale, formulated for the measurement of family function based on the Mac Master pattern. It measures six dimensions of family function including: problem-solving, communication, roles, affective involvement, affective responsiveness and behavior control (Epstein, Baldwin \& Bishop, 1983). The Persian version of the questionnaire has been applied by Najarian (1995). This questionnaire is a valid and reliable measure whose internal consistency was determined for each of the subscales and the total measure using Cronbach alpha- coefficient. The Cronbach alpha for total scale is .91 and for subscales respectively is $.91, .78, .67, .63, .74, .81$ and with Sperman-Brown and Gothman method accordingly is equal to .89 and .88 . The cutoff point was considered 24 for the FAD measurement which separates adjusted couples from maladjusted ones, i.e. a score above it reminds the need for intervention (Zarei \& Younesi, 2009). Respondents were asked to respond to each item on a five-point likert- type scale ranging from 1(strongly agree) to 5 (strongly disagree).

\section{Results}

Descriptive statistics (means and standard deviations) and Multivariate analysis of variance were used in order to analyze the data. Descriptive examination of age and length of marriage variables in the control and experiment groups shows that the average age of the divorce applicant women and men in the experiment group were 23 and 27 respectively and 22 and 28 in the control group. The difference of the average age in both groups was not significant $t(38)=3.98, p>.05)$. Also, the mean length of marriage was 5 years in the experimental group and 4 years in the control group; the differences was not significant $t(38)=2.63, p>.05)$.

Table 1 represents the mean and standard deviations of the components in both experiment and control groups before and after the intervention (note that in the FAD test, high scores indicate weak functioning and low scores indicate strong function).

Table 2 shows that the highest mean belongs to the behavior control dimension (it was 47.15 and 43.25 for the test and control group respectively) with standard deviations of 4.30 (experiment) and 2.77 (Control). The lowest score belongs to the affective involvement (the experimental group received 34.45 with the standard deviation of 2.41 and the control group received 33.45 with the standard deviation of 2.70). See table 1.

Table 1. Descriptive statistic

\begin{tabular}{llllll}
\hline & Group & M. pre test & SD. pre test & M. post test & SD. Post test \\
\hline Problem solving & Experimental & 36.35 & 4.06 & 23.85 & 2.32 \\
& Control & 39.35 & 4.56 & 40.80 & 3.48 \\
Communication & Experimental & 41.75 & 6.60 & 24.70 & 3.19 \\
& Control & 42.15 & 4.48 & 40.50 & 4.17 \\
Roles & Experimental & 39.95 & 5.54 & 24.60 & 3.08 \\
\multirow{3}{*}{ Affective Responsiveness } & Control & 38.05 & 4.82 & 36.35 & 4.34 \\
\multirow{4}{*}{ Affective Involvement } & Experimental & 34.45 & 2.41 & 24.50 & 2.78 \\
& Control & 33.45 & 2.70 & 32.75 & 3.21 \\
Behavior Control & Experimental & 37.45 & 4.61 & 23.65 & 2.36 \\
& Control & 38.90 & 3.95 & 36.25 & 3.07 \\
& Experimental & 47.15 & 4.30 & 26.90 & 1.77 \\
\hline
\end{tabular}

Note. $n=40$. Mean and Standard deviation in Two groups (experimental and control) before and after intervention.

The assumption of the multivariate analysis of variance was developed through an independent t-test. Results showed that there was no significant difference between the experiment and control group in dimensions of Family Function.

The assumption of the parametric was measured by the Box's $M$ test whose value was Box $M=22.43, F=7.05$, $p>.005$, which indicates the normality of the distribution of the scores of the dependant variables in both groups. 
Multivariate Analysis of Variance was implemented to make a comparison between the two groups (experimental and control) to show if they perform differently on the post-test. The value of Lambda Wilks test was $F=19.6$, $p<.05$. As shown in Table 2, the difference between the two groups is significant, indicating that training has improved the mentioned components in the experimental group. The most considerable effect was in the dimension of affective responsiveness (.85) and the least was in the affective involvement (.65). See table 2 .

Table 2. ANOVA

\begin{tabular}{|c|c|c|c|c|c|c|c|}
\hline & Group $(n=40)$ & $\begin{array}{l}\text { Adjusted } \\
\text { mean }\end{array}$ & $\mathrm{f}$ & $\mathrm{df}$ & sig & partial Eta & $\begin{array}{l}\text { observed } \\
\text { Power }\end{array}$ \\
\hline \multirow[t]{2}{*}{ Problem solving } & Experimental & 24.79 & 180.12 & 1 & $.001 * *$ & .83 & .99 \\
\hline & Control & 39.85 & & & & & \\
\hline \multirow[t]{2}{*}{ Communication } & Experimental & 24.70 & 180.62 & 1 & $.001 * *$ & .826 & .99 \\
\hline & Control & 40.50 & & & & & \\
\hline \multirow[t]{2}{*}{ Roles } & Experimental & 24.60 & 98.86 & 1 & $.001 * *$ & .722 & .99 \\
\hline & Control & 36.45 & & & & & \\
\hline \multirow[t]{2}{*}{ Affective Responsiveness } & Experimental & 24.50 & 75.46 & 1 & $.001 * *$ & .655 & .99 \\
\hline & Control & 32.75 & & & & & \\
\hline \multirow[t]{2}{*}{ Affective Involvement } & Experimental & 23.65 & 216.77 & 1 & $.001 * *$ & .851 & .99 \\
\hline & Control & 36.25 & & & & & \\
\hline \multirow[t]{2}{*}{ Behavior Control } & Experimental & 26.42 & 78.06 & 1 & $.001 * *$ & .68 & .99 \\
\hline & Control & 40.57 & & & & & \\
\hline
\end{tabular}

Note. $n=40$. Result of ANOVA and effect of group membership in groups of experimental and control in post test stage. (**significance at the $\mathrm{p}<0.05$ level)

\section{Discussion}

The results indicated that training cognitive techniques (attribution retraining) in an integrated form can improve family functioning in the divorce applicant couples. As observed, in the first hypothesis the level of improvement of the couples in the experimental group has increased in the dimension of roles compared with the control group (see Table 2). The findings of this study are consistent with those of Dattilo and Epstein (2005) on the effect of communicative skill training and role playing on marital satisfaction. Also, Rezakhoo and Younesi (2003) found cognitive techniques and attribution trainings effective in a study into the effect of retraining on attribution styles and increase in marital satisfaction in maladjusted couples. They improved the role component, which has a significant effect on marital satisfaction. The second hypothesis was also confirmed, which showed that the combinational training could improve communication in divorce applicant couples. These findings are consistent with the findings of Dattilo and Epstein (2005) about the effectiveness of training through cognitive-behavioral techniques in reducing relationship problems. From their point of view, communication problems are the main precursor to all marital difficulties. The most prevalent complaint expressed by divorce applicant couples is failure to establish communication. Hosseini (2000) found in her research that cognitive-behavioral interventions improve the relationships of couples more than anything else. Zarei and Younesi (2010) found cognitive training techniques effective in the improvement of family functioning of maladjusted couples.

The third hypothesis was confirmed; it was indicated that training improves problem-solving in divorce applicant couples. These findings are consistent with the findings of Markman and Halweg (1993) on the effect of cognitive intervention on the couples with difficulty in problem-solving. Bacom and Epstein (1990) concluded that cognitive-behavioral trainings not only improved problem-solving skills but also reduced physical violence between couples. Also, training cognitive counseling techniques resulted in the improvement of "affective responsiveness and affective involvement" in the maladjusted couples. These results are consistent with the findings of Weiss and Hyman (1997) which indicate that cognitive interventions such as offering trainings in active expression of affection and other positive emotions lead to an increase in marital satisfaction. In their research on the maladjusted couples who took part in 10 sessions of cognitive interventions, Fincham and Beach (1999) found that training cognitive techniques results in an increase in the intimacy and improvement of the couples' affective relationships. Ellis (1986) found that the casual inference that people make from the observation of their spouses impacts their marital relationship. In another research, Bradbury and Fincham (1990) obtained similar results on the effect of attribution retraining on the couples' general family functioning. 
The important point we should take into consideration in the description of these results is that there is a mutual causal relationship between attributions and family functioning (Bradbury \& Fincham, 1990). As Hornifer and Fincham (1996) stated, individual changes in attributions are in tandem with couples' marital satisfaction, each of which impacts upon the other. When marital attributions change, couples experience better feelings, which not only has a positive effect on the selection of the type of attributions but also increases the level of their family functioning. Moreover, the results are consistent with the works of Burns (2001) in the field of resolving marital problems and his therapeutic program with an emphasis on marital attributions and expectations.

Fincham and Betch (1999) found that couples' satisfaction can change attributions. Also, individual changes are in tandem with attributions and marital satisfaction. Bacom and Epstein (1990) made a comparison between adjusted couples and couples seeking counseling and found that the former group makes safer attributions for their couples' behavior.

In the current research, considering the previous research on marital attributions and their relations with family functioning and marital satisfaction and also the idea of psychologists like Bacom (1991) Fincham and Bradbury (1991) over the fact that attributions can be a useful focal point for marital counseling and techniques, an effort was made to change marital attributions used by couples in order to help them develop a better understanding of marital interaction and obtain new cognition.

Since research of this sort is not common in our country, there are naturally some defects and limitations in the current research, some of which are as follows: the lack of proper understanding of the need for counseling and psychological therapies in resolving marital problems for divorce applicant couples in Iran, the low cooperation of men compared to women, and problems in arranging follow-up sessions. We suggest that such research be conducted more in order to further generalize the findings, and follow-up sessions should be arranged as far as possible.

\section{References}

Amani, A. (2003). Effectiveness of cognitive behavior group therapy on marital satisfaction in women. Journal of Counseling Research \& developments, 9,107-124.

Avidan, D. E., Yahiya, M. M. H., \& Greenbaum, Ch. W. (2009). Divorce is a Part of My Life. Resilience, Survival, and Vulnerability: Young adult's perception of the implications of parental divorce. Journal of Marital and family therapy, 14, 130- 146.

Baucom, D., \& Epstein, N. (1990). Cognitive-behavioral marital therapy. New York: Springer.

Baucom, D., Hosiers, S. L., \& Duher, B. (1989). Attributions style and attribution pattern among married couple. Journal of personality and social psychology, 21, 596-607. http://dx.doi.org/10.1037/0022-3514.56.4.596

Boss, G. (1993). The marital relationship: Boundaries and ambiguities. In A.Cubbin (Eds.), Marriage and relationship (pp.132-144). Washington, DC: American psychiatric press.

Bradbury, T. N., \& Fincham, F. D. (1990). Attributions in marriage. Psychologyical Bulletin, 4, 125-140.

Burns, D. (2001). Summary of cognitive therapy interventions. New York: Springer.

Carlyon, W. D. (1997). Attribution rettrainig:Implications for its integration into perspective social skill training. Journal of Psychology, 12,261-273.

Dattilo, M., \& Epstein, B. (2005). Introduction to the section the role of cognitive -behavioralintervention in couple and family therapy. Journal of marital and family therapy, 31,720-738.

Davoodi, Z. (2009). The effect of brief solution-focused couple therapy approach on decreasing tendency to divorce in Iranian couples. Unpublished master's thesis, University of Isfahan. Iran.

Ellis, A. (1986). Rational-Emotive therapy. In J.Corsini (Ed.), Current psychotherapies (pp.142-185). New York:Wiley.

Epstein, N. B., \& Baucom, D. H. (1993). Cognitive factors in marital disturbance. In. K. S. Dobson \& P. C. Kendal (Eds.), Psychopathological and cognition (pp.112-132). New York: Springer.

Epstein, N. B., \& Baucom, D. H. (2002). Enhanced cognitive -behavioral therapy for couples. A Contextual approach. Washington, D C: American psychiatric press. http://dx.doi.org/10.1037/10481-000

Epstein, N. B., Baldwin, L. M., \& Bishop, D. S. (1983). The McMaster Family assessment device. Journal of marital and family therapy, 9,171-186. http://dx.doi.org/10.1111/j.1752-0606.1983.tb01497.x

Fincham, D., \& Beach, S. K. (1999). Marital conflict, implications for working couples. New York: Wiley. 
Finzi, R., Cohen, O., \& Ram, A. (2000). Attachment and divorce. Journal of family psychotherapy, 11, $121-133$. http://dx.doi.org/10.1300/J085v11n01_01

Forsterling, F. (2001). Attribution retraining. Milton Keynes: Academic Press.

Goldenberg, I., \& Goldenberg, H. (2008). Family Therapy an overview: Handbook of Family therapy. New York: thomson.

Gottman, J. M. (1983). Divorce in psychosocial perspective: Theory and research. New Jersy: Lawrence Erlbaum.

Gottman, J. M. (1996). What Predicates Divorce? Hillsdale, NJ: Erlbaum.

Holley, P. (2006). The Relationship between Intelligence and Divorce. Journal of Family Issues, 27, $1723-1748$. http://dx.doi.org/10.1177/0192513X06291887

Holtzwrth, A., Munero, A., \& Jacobson, W. S. (1985). Casual attributions and married couples. Journal of personality and social psychology, 3, 412-432.

Horneffer, K. J., \& Fincham, F. D. (1996). Attributtinal models of depression and marital distress. Journal of personality and psychology, 22, 47-59.

Hosseini, Z. (2000). Examination of cognitive behavioral therapy on improvement of marital satisfaction. Journal of counseling research \& developments, 3, 20-34.

Kalmjin, M., \& Uunk, W. (2007). Regional Differences in Europe and the Social Consequences of Divorce: A Test of the Stigmatization Hypothesis. Social Science Research, 36, 447-468. http://dx.doi.org/10.1016/j.ssresearch.2006.06.001

Kelly, G. (1963). A Theory of Personality, The Psychology of Personal Constructs. NewYork: Norton.

Leahy, R. L. (2008). Cognitive therapy:Basic prinsiples and applicatons. NewJersy: Academic press.

Leonard, K. E., \& Roberts, I. J. (1998). Marital aggression, quality and stability in the first year of marriage. New York: Cambridge university press.

Mark man, H. J., \& Hahlweg, K. (1993). The prediction and prevention of marital distress: An interactional perspective. journal of clinical psychology review, 2(13), 29-38.

Najarian, F. (1995). Standardize FAD family function inventory in Iran. Journal of research in family, 2, 23-35.

Rezakho, A. A., \& Younesi, J. (2003). Retraining of attribution styles on increasing marital satisfaction in mal adjusted couples. Journal of social worker, 4, 44-51.

Sutton, M. (1983). Defining divorce adjustment: A study of marriage and family therapist's criteria for construction long -term adjustment to divorce. Unpublished doctoral dissertation, university of Missouri, Columbia.

Teasdale, J. D. (1993). Emotion and two kinds of thinking. Cognitive therapy and cognitive sciences. Hillsdale, NJ: Erlbaum.

Walsh, F. (1988).The family in later life. In B. Carter and M, Goldrick. (Eds.), The change family life cycle: A Frame work for family therapy (pp.517-532). Washington, DC: American psychiatric press.

Weary, G., \& Harvey, J. H. (2001). Evaluation in attributional process. Journal for the theory of social behavior, 11, 193-208.

Weiss, R. L., \& Hyman, R. E. (1997). A clinical-research overview of couple's interactions. Clinical hand book of marriage and couples interview. SanDiego, CA: Academic press.

Young, J. E., \& Long, L. (1998). Counseling and therapy for couples. New york: Guilford press.

Zarei, H., \& Younesi, J. (2009). The effectiveness of cognitive techniques on improvement of family function in mal adjusted couples. Journal of Daneshvar Raftar, 29, 35-52. 